\title{
Theory and Research in Education
}

http://tre.sagepub.com

Can intimacy justify home education?

Michael S. Merry and Charles Howell

Theory and Research in Education 2009; 7; 363

DOI: $10.1177 / 1477878509343193$

The online version of this article can be found at: http://tre.sagepub.com/cgi/content/abstract/7/3/363

\author{
Published by: \\ (SAGE \\ http://www.sagepublications.com
}

Additional services and information for Theory and Research in Education can be found at:

Email Alerts: http://tre.sagepub.com/cgi/alerts

Subscriptions: http://tre.sagepub.com/subscriptions

Reprints: http://www.sagepub.com/journalsReprints.nav

Permissions: http://www.sagepub.co.uk/journalsPermissions.nav

Citations http://tre.sagepub.com/cgi/content/refs/7/3/363 


\title{
Can intimacy justify home education?
}

\author{
M I C H A E L S . ME R R Y \\ University of Amsterdam, the Netherlands \\ C H A R L ES H O W E L L \\ Northern Illinois University, USA
}

\begin{abstract}
A B S T R A C T
Many parents cite intimacy as one of their reasons for deciding to educate at home. It seems intuitively obvious that home education is conducive to intimacy because of the increased time families spend together. Yet what is not clear is whether intimacy can provide justification for one's decision to home educate. To see whether this is so, we introduce the concept of 'attentive parenting', which encompasses a set of family characteristics, and we examine whether and under what conditions attentive parents risk loss of intimacy by sending their children to school; or, alternatively, whether they can avoid this risk by educating children at home. What we will determine is whether families who exhibit the specified characteristics are prima facie justified in educating their children at home under the conditions of interest. We argue that, for attentive parents, home education not only promotes greater intimacy, but also provides insurance against the loss of intimacy that may occur under certain conditions when children attend schools.
\end{abstract}

KEYW ORDS attentive parenting, home education, intimacy

A PARENT'S LOVE FOR A CHILD, when fully realized, is without parallel in human experience. Parents know their children as no one else knows them. Parents who love well love unconditionally. Robert Frost's (I9I5) line about home - 'the place where, when you have to go there, they have to take you in' - speaks to the force of all kinship ties, but most importantly, to the tie between parent and child.

Fully realized parental love creates a relationship with specific and psychologically important characteristics which are commonly summed up by the term intimacy. In this article, we explore the relationship between intimacy

\section{Theory and Research in Education}

Copyright (C) 2009, SAGE PUblications, www.sagepublications.com VOL 7 (3) 363-38I ISSN I 477-8785 DOI: IO.II 77/I 477878509343 I 93 
and home education. We argue that intimacy is both a good in itself and a source of other important goods. Further, it is an essential and irreplaceable good, like life itself or basic nourishment. That is, it cannot be traded against other goods, i.e. more money, popularity, health or educational opportunity cannot compensate for the loss of intimacy.

Parents who educate children at home have many motivations, including improved academic performance, the transmission of personal beliefs, special needs accommodation, or adapting instruction to a child's learning style (Collom, 2005; Duvall, 2005; Isenberg, 2007; Jeub, I994; Rothermel, 2003; Van Galen, 1987). Yet many also cite intimacy as one of their reasons for their choice (Mayberry and Knowles, I989; Mayberry et al., I995). But does this reason provide justification for their choice? It seems intuitively obvious that home education is conducive to intimacy because of the increased time families spend together. But are there any conditions under which home education is essential to intimacy?

Educational choices are immensely complex. To evaluate their impact on intimacy, we have to make some simplifying assumptions. Of these, the most important concerns characteristics of the family making the choice. To sharpen the analytical focus, we introduce the concept of 'attentive parenting', which encompasses a set of family characteristics, the effects of which on children's development have been extensively studied. We examine whether and under what conditions attentive parents risk loss of intimacy by sending their children to school; or, alternatively, whether they can avoid this risk by educating children at home.

The intended result of this exploration is not a comprehensive justification of home education, but rather a much narrower prima facie justification. What we are seeking to determine is whether families who exhibit the specified characteristics are prima facie justified in educating their children at home under the conditions of interest. Where characteristics or conditions diverge from those specified, justification would need to be reevaluated on a case-bycase basis. Even where they do not diverge, our conclusion about intimacy does not settle the justificatory question. Education obviously involves other essential and irreplaceable goods: citizenship, autonomy and life chances, among others. These other goods lie beyond the scope of our article, except insofar as they are directly affected by intimacy.

We will proceed as follows: first, we will examine the nature of intimacy and explain why it is both a good in itself, vital to human flourishing, and a source of other goods. Second, we will examine how intimacy develops in the parent-child relationship. This account highlights the importance of intimacy in parents' decision to educate children at home, even when they 
cite other, more specific concerns as their primary reasons. Third, we will lay out the central argument concerning the effects of home education in fostering intimacy. We will argue that, for attentive parents, home education not only promotes greater intimacy, but also provides insurance against the loss of intimacy that may occur under certain conditions when children attend schools. We do not make the more controversial claim that attending school necessarily reduces parent-child intimacy.

We then consider three values which, under certain conditions, could come into conflict with the value of intimacy. These are (I) critical thinking and autonomy, (2) equality of educational opportunity and (3) the public goods that a system of universal public education is thought to provide. All three of these values raise similar issues about home education in general and enhanced intimacy as a specific feature of home education in particular. A full exploration of the implications of all three is beyond the scope of this article, so we discuss critical thinking and equal opportunity only briefly, and select public goods for more detailed examination in the hope that it will provide an illustration of the approach to be used in assessing the others.

\section{THE NATURE OF INTIMACY}

To establish intimacy as an irreplaceable good, and to evaluate its implications for educational choices, we must first say what it is. Intimacy is a characteristic of relationships, not of individuals. The core meaning of the term can be seen in a variety of relationships such as close friendships, romantic love and family ties. Not all popular usages of the term, however, fit this core meaning. Intimacy as a euphemism for sexual intercourse does not capture essential characteristics such as trust and mutual knowledge. 'Unwanted intimacy' - an unwelcome overture from one person to another - is really not intimacy at all, since it refers to one person's presumptuous behavior, not to a relationship.

The core examples of intimacy exhibit common characteristics. They all involve (I) affection, (2) mutual knowledge, (3) shared experience, (4) open communication and (5) trust. These five characteristics are all necessary conditions of intimacy. A relationship that lacked any one of them could not be considered intimate. Moreover, they are jointly sufficient - any relationship that included all of them would count as intimate.

Intimacy is essential to human well-being because it provides the foundation for mutual care between two people. Without the five characteristics, mutual care would not be possible. Without mutual knowledge, two people could not effectively help one another; without affection, they would lack motivation to help in a sustained way; without communication, they could not 
maintain mutual knowledge; without trust, they would be unwilling to share sensitive personal information.

Besides providing the foundation for mutual care, intimacy is also the source of other important goods. Lack of intimacy breeds loneliness, increased stress and accelerated physical deterioration; intimacy does the opposite, providing a buffer against life's indignities and disappointments. Intimacy also contributes to the flourishing of children. Family intimacy makes children feel secure and is strongly associated with healthy social development. Lawrence Thomas (2006: 20) summarizes the conditions that generate intimacy between parents and children:

[The] simple but ever so powerful presumption that comes in the wake of parental love is that the child's very existence was, and continues to be, wanted. Thus, it is not just the fact that a child is loved. There is the absolutely extraordinary consideration that the child was brought into being in order to be loved. Moreover, there is not just an acceptance of the child's flourishing, but a commitment to this taking place. Accordingly, a child's sense of worth is properly underwritten when, and only when, the child experiences the behaviour of its parents on its behalf as an immutable commitment to its well-being that they did not have to have, but chose to have.

Parents' love for the child begins in infancy, when the child can do nothing for herself. The neediness of the infant, parents' satisfaction in meeting the needs, and the infant's pleasure and contentment create an atmosphere of warmth, security and affection. From these early experiences, the child learns to trust that parents will meet her needs. This trust, known in the psychological research literature as attachment (Bowlby, I982), resonates throughout childhood development and across the lifespan. More immediately, it motivates the child to continue to make her needs known.

Parents, for their part, are profoundly affected by the process of meeting the child's needs. They experience gratification, which intensifies love and heightens their vigilance and determination to continue meeting the child's needs. But gratification is not parents' only motive for attending to the child's needs. The child's helplessness drives home the depth of their responsibility to protect, nurture and guide the child toward self-sufficiency (Sidgwick, I962). Further, the parents' love for and investment in the child make them uniquely vulnerable. The prospect of harm to the child is unspeakably painful. Better that one should die oneself than see one's child die. Hence the common perception that the worst fate life has to offer is surviving one's offspring.

As the child develops, the relationship changes. Children remain vulnerable, requiring protection, but they also inevitably become more independent. They develop their own interests and projects. These require room to develop as well as respect from the parents. And with respect for the child 
as an agent-in-the-making, a parent's duty becomes more complex. Thomas explains:

Love is incompatible with the arbitrary treatment of another; and the only way for love to be nonarbitrary is that it is anchored in a conception of the right. By contrast, the only way for treating a child in accordance with a conception of the right, without seeming as if it were a burden, is for acting in accordance with the right to be animated by love. (2006: 90)

The conception of [the] right is multifaceted. It combines duties of protection and nurture, the duty to cultivate the child's developing agency, and the twofold duty to help the child develop a sense of justice and to do one's own part to ensure a society hospitable to that sense of justice. As Thomas indicates, love provides motivation for the discharge of these duties. Yet love by itself is not sufficient. Without knowledge and concern for what is right, love risks going astray. Indeed, great harm can be committed in the name of love.

Yet notice how intimacy, properly understood, contains both features: love and knowledge. Certainly it is nourished by unconditional love, yet because intimacy entails knowledge of the needs, wishes and interests of the other, it will be properly guided by considerations for the child's well-being. So while the goods associated with intimacy accrue to all parties participating in it, the paternalistic qualities of intimacy from the parental side of things must include the recognition that her needs cannot simply be swallowed up in the egoistic pursuits of the parent. If the care and concern for one's child means anything, it surely includes the desire to look after her development in a very particular way, and looking after what is best for one's child will include the sort of education she receives.

Indeed, parents who home educate exhibit a level of commitment, love and concern one should hesitate to criticise. And it is certainly true that most parents acquire a new appreciation both for the sorts of skills required for educating a child well, and also for their own limitations in delivering on the skills required. The investment of time, love, energy and patience is nothing if not impressive. This does not mean that parents are faultless or that only parents exhibit the features of intimacy we describe and defend. Nevertheless, the decision to home educate based in part on the benefits of intimacy seems intuitively correct.

As we have seen, however, there are important limits on what intimacy will, or ought, to allow. In the name of intimacy, parents may not do with, for, or to their children anything they want. In other words, notwithstanding its important value, intimacy cannot and should not be used as a front for unrestrained parental prerogatives or authoritarian parental control. Remember that intimacy, properly construed, will entail love balanced against 
conceptions of what is right. As separate agents-in-development, children must still be morally seen as ends-in-themselves. So, while arguments that emphasize parental freedoms in choosing an education deemed appropriate for one's own child are warranted (and widely protected by constitutional law), defences of home education which argue strictly on the basis of parents' wishes - particularly if derived from libertarian notions of self-ownership assume parental entitlements that cannot be defended against the independent interests of children. Thus, those who would disingenuously argue from intimacy in order to govern the content and direction of a child's education without regard for the needs, wishes or interests of a child are untenable from the standpoint of justice. Therefore, notwithstanding the incidental value of intimacy, our argument will not support contestable claims of parental entitlement.

\section{HOME EDUCATION AND THE GOOD OF INTIMACY}

Intimacy, we have argued, is a good in itself and also a source of other goods that aid in children's flourishing and development. But is home education conducive to intimacy? Is it more conducive to intimacy than education in schools?

To make this comparison, we must first specify the home environment that is to be compared with the school. As many scholars have reported, the actual practices of families that educate their children at home vary widely (Stevens, 200I; Van Galen, I99I; Wyatt, 2008). To evaluate the relationship between home education and intimacy, essential common features of these divergent practices must be abstracted. If a clear link between intimacy and the essential features can be established, then the connection between home education and one of life's most important goods will be demonstrated. This connection provides prima facie justification for educating children at home. Nonessential or contingent features of home education in specific families would then need to be evaluated on a case-by-case basis to determine whether these specific instances are covered by the justificatory argument.

How, then, are essential common features to be identified? One promising approach, suggested by Wyatt (2008), is to examine characteristics associated with persistence in home education; or, conversely, with its abandonment. The former generate sustainable practices, which may be considered essential; the latter do not, and hence clearly are not sustainable and consequently may be considered contingent.

For some, perhaps many, families, home education does not work well. Parents set out with unrealistic expectations about discipline, control or academic achievement. They are not sufficiently attentive to their children's 
needs, and do not adapt creatively to their interests and capabilities. Their efforts to control or motivate their children generate conflict. Tensions within the family escalate. Wyatt argues that it is this escalation that is most likely to cause parents to abandon the attempt to educate children at home. Indeed, a significant number of those who set out to home educate quit within the first year.

Rigid, controlling strategies generate instability and hence lead to the abandonment of home education. Conversely, strategies that strengthen family relationships yield satisfaction, which Wyatt identifies as the chief motivation for families that persist in home education. Many researchers have found that families frequently mentioned strengthened relationships as one of the chief benefits of home education. Others include the ability to respond to the child's needs, improved communication, and enhanced confidence on the part of the child (Mayberry et al., I995; Mayberry and Knowles, 1989). These results, in contrast to the inflexible, controlling strategies that Wyatt associates with instability, supply the essential background characteristics of successful home education.

Empirical research on parenting strategies provides more detail about what this environment would look like. A number of behavioral characteristics have been found to be associated with reduced conflict and enhanced mutual satisfaction between parents and children (Grusec and Goodnow, I994). For convenience, we will refer to this set of characteristics as attentive parenting. Chief among these characteristics are: (I) sensitivity to a child's abilities, knowledge, beliefs, moods and developmental characteristics, and their willingness to adapt expectations in light of this information; (2) warmth, affection and humor, because they alleviate stress and reduce the likelihood of antagonism; (3) a willingness to explain one's expectations, which helps children to understand, and potentially to accept, the reasons behind parental values, and also to generalize expectations to new situations; (4) parental sincerity, which contributes to a child's acceptance of social and moral norms because children are particularly astute as recognizing hypocrisy; finally ( 5 ) a capacity to employ inductive reasoning, which supports independent decision-making, and thinking through the consequences of different courses of action.

The empirical literature clearly establishes all of these factors as contributing to a child's internalization of her parents' values. Attentive parenting therefore makes conflict within the family less likely, and thus these factors should be considered essential features of home education. While the converse characteristics may not lead directly to the abandonment of home education, they tend to increase family tension and consequently make continuation of the project more difficult. Harsh, unyielding, insensitive, unexplained, ill-humored, unloving and over-controlling parental discipline practices may 
exist in families that educate children at home, but these are non-essential characteristics that do not affect the argument presented here.

Attentive parenting, in short, delineates a set of characteristics which, we argue, are essential to home education. However, these characteristics cannot by themselves be used to argue for a link between home education and intimacy. Obviously attentive parenting is not limited to families that educate children at home; if such practices weren't widely represented in the general population of parents, researchers would not have been able to establish their beneficial effects. Thus we must also ask whether home education is more conducive to intimacy than other forms of education in which parents (and perhaps also teachers) exhibit similar characteristics.

A preliminary reading of the five characteristics of intimate relationships indicates that while these are available to all families, regardless of their mode of education, families who educate their children at home enjoy an obvious advantage in two areas: mutual knowledge and shared experience. Children educated at home are bound to spend more of their day with one or both parents; hence, where parents adhere to the norms of attentive parenting, shared experience and mutual knowledge will be more extensive. But does this quantitative difference, important as it may be, affect the quality of intimacy that children enjoy within the family? A difference in degree may strengthen the overall case for home education, but it can hardly provide prima facie justification. We have identified intimacy as an irreplaceable good, but not as the only good. If home education supplies more of it, the gain must be weighed against effects in other areas. Only if it can be shown that home education preserves intimacy that might be lost if children were sent to school does the claim of prima facie justification become plausible.

What we need to establish, then, is not just that one group of parents has more knowledge and shared experience than another, but that the kind of knowledge and experience one group has and the other group lacks is of a kind that may affect the possibility of intimacy. Is there a kind of unshared experience or an aspect of a child's life hidden from parents that could preclude or disrupt intimacy? Three areas of experience seem relevant here: failure, bullying and exposure to risk-taking behavior.

\section{Failure}

Failure covers a lot of ground. It relates to schoolwork, friendship or feelings that arise from the perception that one's teachers or peers are disapproving in some way. Nearly everyone experiences failure at some time during childhood. The results need not be harmful. One can learn from failure. It can be the source of powerful motivation, an impetus to seek help, and ultimately 
a step toward accomplishment. For children educated at home, the parent lives through the child's agonizing experience in real time. If the child goes to school, parents may live through it retrospectively at the family dinner table. For these children, failure creates a new shared family experience. As uncomfortable as this might be for parents, family intimacy is likely to be strengthened rather than compromised.

Many children, however, turn inward. They feel ashamed or embarrassed. They exhibit what is known in the psychological literature as 'avoidant motivational orientation'. They avoid challenges that might reveal their inadequacy. Rather than admit their frustration, they conceal it behind a façade of confidence or indifference. They affect not to care about grades or academic learning or college prospects. In short, the initial failure is compounded by a defensive or avoidant response, leading to additional failures that compound the child's sense of inadequacy. In effect, the first frustration sets in motion a cycle of failure.

When a child spirals downward, circumstances may make it very difficult for parents to identify what the problem is. If the child can't or won't explain, a gulf is created. The parent can no longer help. The parent no longer has access to the child's feelings and needs. Each month that passes without interruption of the cycle of failure, the gulf widens. The child becomes increasingly shut off from the parent. Intimacy is compromised. It is not just that the degree of intimacy decreases marginally. For the major part of the child's life, it simply ceases. The child and the parent might as well inhabit different worlds.

Children educated at home are much less likely to get caught up in this cycle than children educated at school, assuming attentive parenting in both cases. Granted, the personality of the child influences the outcome, and so does the quality of the teaching for children in school. But, other things being equal, it is easier to hide in a crowd. A teacher, even if highly skilled, is much more likely to miss the signs of frustration in a class of 20 to 30 age peers than attentive parents responsible for just their own family. For a child educated at home, the parent's physical proximity, emotional availability and direct supervisory responsibility greatly diminish the likelihood of this type of cycle of failure.

\section{Bullying}

The second type of unshared experience that can create a gulf between parents and children is bullying. Research in several countries clearly indicates that bullying and harassment are widespread in public schools (Shepherd, 2009; Anon, 2009). The Digest of Education Statistics reports that, in 2007, between 
$4.7 \%$ and $6.5 \%$ (depending on the grade level) of American high-school students felt too unsafe to go to school; $6.3 \%$ to $9.2 \%$ had been threatened or injured on school property; $8.6 \%$ to $\mathrm{I} 7 \%$ had been engaged in a fight; and $22.9 \%$ to $29 \%$ had had property stolen or deliberately damaged on school property (Snyder et al., 2009: 238). An even larger proportion of students witness bullying. Effects of this exposure can include anxiety, fear, depression, dissociation, decreased academic performance, decreased overall health and truancy (Flannery et al., 2004). According to the US Health Resources and Service Administration (n.d.), children are often unwilling to talk with adults about bullying because of shame, hopelessness and the belief that there is nothing adults can do to stop bullying, even if they are willing to try. The downward spiral of victimization, emotional distress and loss of trust in adults compromises intimacy in much the same way as academic failure.

Granted, children educated at home are not immune from bullying and harassment: organized community groups, social activities and neighborhood play are all sites of potential exposure. Home education, however, greatly reduces the chance of the downward spiral. Parents are more emotionally available, the time of exposure is greatly reduced and, unlike in school, children can end the bullying simply by walking away from the group or activity.

\section{Risk-taking behavior}

The third type of unshared experience is exposure to drug and alcohol use, early sexual activity, and other illicit and/or risk-taking behavior. Once again, these have emotional, physical and academic consequences for young people. If children are exposed to this type of behavior, either as witnesses or participants, they are likely not to share this experience with adults, and a similar downward spiral can result. While children educated at home are not immune from exposure, they can walk away much more easily than those who attend school. Parents are more readily available. Perhaps most important in this case, it is not as easy for children educated at home to use peer groups to shield themselves from adult scrutiny.

Of course school attendance does not guarantee disruption of family intimacy. It does, however, create conditions that make disruption of intimacy more likely. The downward spiral described here occurs when adults are shut out of a significant portion of children's lives. For attentive parents, sending children to school may be the most likely cause of the exclusion. For this reason, the cycle of depression, failure, and hopelessness can be seen as pathologies of schooling. 
Home education provides a kind of insurance against such disruption. Granted, the insurance policy is not absolute. But parents are in a much better position to maintain open communication with the child, to be aware of what the child is experiencing, and to intervene if necessary to stop the cycle. In short, they are in a better position to maintain family intimacy. The advantages of this arrangement, and the insurance that it provides against pathologies of schooling, provide prima facie justification for home education.

\section{IMPORTANT VALUES THAT MAY COME INTO CONFLICT WITH INTIMACY}

While the argument from intimacy may provide prima facie justification for a family's decision to educate children at home, an all-things-considered justification would require a wide-ranging examination of all the goods and ills that might be affected by such a decision. These values include the promotion of critical thinking and autonomy, educational equality and the public goods generated by a universal system of public education. In what follows we briefly explain why the first two values are important, and also how they might, in some circumstances, count against home education. We then set these aside in order to focus on public goods. In the course of this discussion, we will show that, while these values may conflict with intimacy, they do not necessarily do so; whether they do or not depends on societal conditions as well as the circumstances faced by particular families.

\section{Critical thinking and autonomy}

The first good that may conflict with the value of intimacy is critical thinking and autonomy. Both are valued because they demonstrate a capacity to reflect upon one's judgments, as well as a capacity to formulate, revise and pursue a way of life one can identify with from the inside. Those who prize critical thinking and autonomy are perhaps especially worried about families who educate children at home in order to impart religious values to them (Kunzman, 2009), ${ }^{\mathrm{I}}$ though even families of secular orientation often have strong values that they want to inculcate in their children.

Educating children at home might allow parents to limit their exposure to value systems and ways of life unlike those of the parents. When children do come into contact with competing value systems, parents who educate their children at home have greater opportunity to steer or manipulate children's evaluation of these value systems. Finally, if the home environment is extremely restrictive, children will have fewer opportunities for self-expression beyond 
the reach of parental supervision, and thus fewer opportunities to explore their own thinking and form and test independent judgment.

This scenario is obviously possible, but whether the conflict envisioned actually arises depends on a number of factors. First, do families in general, or a particular family, really seek to limit exposure, and if so are they successful in doing so? To what extent does the system of schools, or a particular school of interest, promote exposure, and how successful is it in doing so?

Parallel questions would need to be asked about manipulating children's evaluation and about opportunities for independent expression. Restrictive and manipulative aspects of the school and peer influence should also be taken into account in this assessment.

Finally, the connection to intimacy must be considered. It should be obvious that restriction of critical thinking is not essential to intimacy. Intimacy can be pursued in home education without it. But one must take a step further and ask whether restrictive parenting practices tend to promote or to discourage intimacy. If they discourage it, then not only do the values of family intimacy and critical thinking not conflict, but they complement one another.

Whether or not the value of critical thinking and autonomy conflict with intimacy, in short, depends on societal conditions, the circumstances of particular families and facts about psychosocial development.

\section{Equality of educational opportunity}

The argument for educational equality takes many forms, but in simple terms its value lies in leveling the playing field so that all children, irrespective of background variables such as wealth or ability, enjoy equal learning opportunities insofar as this is economically possible and can be achieved without encroachment on basic liberties (Merry, 2008). Given that families who educate children at home are overwhelmingly two-parent families and tend to be wealthier and better educated, benefits derived from this educational choice seem likely to increase social inequality. Critics of home and private education have pointed out that removal of relatively privileged children from public schools not only advantages those children but also potentially compromises the quality of education for those left behind (Clayton and Stevens, 2004).

According to this scenario, pathologies of schooling could be intensified if those parents disposed to resist removed their children - and their influence from public schools and focused their efforts at home where only their own children benefit. If so, then restricting home education (as well as private education) could have the effect of ameliorating the pathologies of schooling, 
thus potentially enhancing intimacy for all, not just a few. Thus the intimacy argument might work against home education rather than in favor of it.

Once again, the force of these arguments depends on a number of factors: the extent to which parents, individually or collectively, can influence schools that their children attend over and above the influence they exercise as citizens; the circumstances of individual families who must decide whether or not to remove their children from school, as well as the conditions in the specific schools those children attend; and the circumstances of families who do not contemplate such a choice, in particular their capacity to take advantage of increased opportunities for intimacy when pathologies of schooling are ameliorated. Some of these factors parallel issues that arise for public goods as well, and we consider those in detail below.

\section{Public goods}

We now come to the conflicting value of public goods. A public good is a good which, because of its structure, must be available for anyone to enjoy if anyone is to enjoy it. The market undersupplies public goods because there is no way to prevent those who don't pay from enjoying them. Hence the state must step in to supply, at the expense of all, the goods people collectively want but could not obtain if they had to choose individually.

An effective system of public schools is widely recognized as a public good. In theory, public schools produce an educated workforce, a well-informed citizenry, and a civil society in which people recognize their rights and responsibilities to one another. No one can enjoy these benefits unless they are available to all to enjoy.

One might think that the free-rider problem would be resolved through payment of taxes. Citizens decide collectively what level of education they want and set the tax rate accordingly. Lubienski (2000), however, argues that the economic cost of public education is not the full cost. We must also consider families' sacrifice in sending their children to public schools rather than educating them at home or in private schools. If the good of public schools derives at least in part from their universality, then defection to private schools and home education reduces supply of the good. A variety of reasons are given for this contention, of which two deserve mention here. First, public schools are one of the few places in which people of different backgrounds intermingle and share their concerns, and that experience makes for a more inclusive and respectful society (Anderson, 2007). Second, the participation of middle- and upper-middle-class families in particular brings their influence to bear in support of the schools and thus improves their quality (Swift, 2003). 
If these two claims are accepted, then the argument from intimacy would lose much of its force. Granted, intimacy is an irreplaceable good, but so are good public schools and an inclusive and respectful society. An additional argument would have to be found for deciding which of these sets of values is to prevail over the others. There are, however, several good reasons to reject this suggestion.

First, the empirical premises are suspect. In virtually all industrialized societies, schools are stratified by culture, social class or race and hence are not as heterogeneous as one may like to think. ${ }^{2}$ Even well-integrated schools are rarely integrated at the classroom level, and the differentiated effects are dramatic (Gamoran et al., I995; Ogbu, 1994). Second, unless schools have consciously altered their organizational structure, research on parental involvement suggests that parents, middle-class or otherwise, have little substantive influence on how schools are run (Comer and Haynes, I99I; Epstein, 200I; Fine, 1993). Schools typically invite parental participation in projects in which the agenda is tightly controlled by the school. The role of the parents is restricted to fund-raising or volunteering at school events or in classrooms. Where parents, particularly from the middle class, do appear to have significant influence is in calling attention to the particular needs of their own children. But there is no empirical evidence to support the claim that parental involvement improves the overall quality of schools.

Even if we concede that some, perhaps even many, schools do have the characteristics implied by the value of public goods, the argument from intimacy is not refuted, but merely restricted in scope. To see why, consider Clearwater School, where parental involvement has made an enormous difference. Because of parental involvement, bullying has been greatly reduced, children's individual learning needs are consistently met in the classrooms, and illicit activity is either nonexistent or so rare that most students are not even aware of it.

Suppose that the Smiths are considering sending their child to Clearwater. Recall, however, that the intimacy argument depends on the possibility of unshared experience undercutting the child's trust in parents and the parent's ability to respond to the needs of the child. At Clearwater parental involvement is high. The level of unshared experience is reduced. Furthermore, the kinds of experience that parents do not share are not the kind that result in the distress, downward spiral or cycle of failure discussed in the last section. Hence in this case, parents do not need to ensure against disruption of intimacy. The intimacy argument simply does not apply.

Generalizing from this example, we can see that in the very cases in which the public goods objection has real purchase, the intimacy argument 
isn't available. Hence, whatever the strength of this competing value against non-public educational choices in general, it does not appear to be relevant to the argument that we have defended.

\section{O N C L U S I O N}

In this article our aim has not been to stack the deck in favor of home education by valorizing what parents are uniquely qualified to do but merely to assess whether intimacy might provide a prima facie justification for educating one's child at home. We have not argued that home education is the exclusive site of attentive parenting, or that home education unfailingly yields positive outcomes in contrast to an alleged 'common school nightmare' (Erickson, 2005). The negative experiences we use to illustrate the value of intimacy, viz., failure, bullying and exposure to risk-taking behavior, are clearly not problems that beset all schools or school age children, and there is nothing in our argument which precludes these from happening to children who are educated at home. We have not argued that these items fall outside of the realm of possibility for home educated children but merely that intimacy - as we have defended it - provides prima facie justification for attentive parents who choose to insure against the disruptive effects of schooling pathologies by educating their children at home.

It is important, however, to be clear about the extent and limitations of this argument. First, as we have shown, the intimacy argument does not apply in cases of authoritarianism where parents are inattentive to their children's needs or where parents resort to coercion or other forms of psychological manipulation. These characteristics tend to discourage family intimacy by creating a wall between parents and children. Measures to insure against disruption of family intimacy by conditions at school are therefore not needed.

Second, the argument from intimacy does not obligate attentive parents to educate their children at home regardless of circumstances; nor does it forbid them from sending their child to school. As we have seen, children's susceptibility to the pathologies of schooling depends both on individual and school characteristics. The argument implies, however, that, where susceptibility is high, not to insure against disruption of intimacy risks grave harm to the child. Under these circumstances, educating a child at home may not be just a defensible choice but a positive duty.

We acknowledge that intimacy is not the only value to be considered when a society decides whether to allow and/or encourage home education, or when an individual family deliberates over whether to remove a child from public school. Three important values - critical thinking, equal 
educational opportunity and public goods - are potentially affected by these decisions. Depending on circumstances, the pursuit of intimacy could come into conflict with these values. However, as the case of Clearwater School illustrates, in the ideal school setting the intimacy argument has little force. It comes into play only when schools do not function effectively and when children's needs are not met there. In fact, as shown in the previous section, the intimacy argument and the public goods objection closely complement one another. The intimacy argument is strongest where conditions envisioned by the public goods argument are not satisfied, and conversely. A more extended discussion would show that this is true for critical thinking and equal educational opportunity as well.

The intimacy argument is not the only route to the justification of home education. Advocates argue that increased academic performance, emotional health, transmission of religious values, and even children's independence are enhanced when they are educated in the home. The intimacy argument is particularly compelling, though, in that it does not depend on dubious empirical premises about educational outcomes or controversial claims about the worth of a specifically religious outlook on life. The force of this argument should be examined carefully by policymakers as they consider whether to raise or lower barriers to parents who seek to preserve and enhance family intimacy by educating children at home.

\section{N O T E S}

1. While evidence (Kunzman, 2009; Stevens, 200I) in the US suggests that religious belief is an important motivation, elsewhere the evidence demonstrates that religious motivations represent only a small minority of parents who home educate (Blok, 2004; Brabant et al., 2003; Gabb, 2005; Spiegler, 2004; De Waal and Theron, 2005).

2. The literature on stratification is vast, and critics normally single out the US or the UK. Yet stratification between different social class and ethic/racial groups is also highly visible on the European continent. The phenomenon is so widespread in the Netherlands, for example, that schools are simply called 'white' or 'black', and more equitable funding schemes do not even begin to curtail this trend (Vedder, 2006). But this phenomenon is not restricted to Western societies. Even in industrialized Asian societies, similar evidence can be found (Kariya and Rosenbaum, I999).

\section{REFERENCES}

Anderson, E. (2007) 'Fair equality in education: a democratic equality perspective', Ethics I I7: 595-622. 


\section{Merry and Howell: Can intimacy justify home education?}

Anon (2009) 'Experts look to reduce bullying'. Available at http://news. bbc.co.uk/2/hi/uk_news/wales/childhood/795I347.stm (accessed 3I March 2009).

Blok, H. (2004) 'Performance in home schooling: an argument against compulsory schooling in the Netherlands', International Review of Education 50: 39-52.

Bowlby, J. (1982) Attachment. New York: Basic Books.

Brabant, C., Bourdon, S. and Jutras, F. (2003) 'Home education in Quebec: family first', Evaluation and Research in Education I 7: I I 2-3 I.

Clayton, M. and Stevens, D. (2004) 'School choice and the burdens of justice', Theory and Research in Education 2(2): I I I-26.

Collum, E. (2005) 'The ins and outs of parental motivations and student achievement', Education and Urban Society 37(3): 307-35.

Comer, J.P. and Haynes, N.M. (I99I) 'Parental involvement in schools: an ecological approach', The Elementary School Journal 9I(3): 27I-77.

De Waal, E. and Theron, T. (2005) 'Homeschooling as an alternative form of educational provision in South Africa and the USA', Evaluation and Research in Education I 8: $144-56$.

Duvall, S. (2005) 'The effectiveness of homeschooling students with special needs', in B. Cooper (ed.) Homeschooling in Full View: A Reader, pp. I5 I-66. Greenwich: Information Age Publishing.

Epstein, J. (200I) School, Family and Community Partnerships: Preparing Educators And Improving Schools. Boulder, CA: Westview Press.

Erickson, D. (2005) 'Homeschooling and the common school nightmare', in B. Cooper (ed.) Homeschooling in Full View: A Reader, pp. 21-44. Greenwich: Information Age Publishing.

Fine, M. (I993) '(Ap)parent involvement: reflections on parents, power and urban public schools', Teachers College Record 94(4): 682-729.

Flannery, D.J., Wester, K.L. and Singer, M.I. (2004) 'Impact of exposure to violence in school on child and adolescent mental health and behavior', Journal of Community Psychology 32(5): 559-73.

Frost, R. (I9IS) North of Boston. New York: Henry Holt and Company.

Gabb, S. (2005) 'Homeschooling: a British perspective', in Home Schooling in Full View: A Reader, pp. I99-227. Greenwich: Information Age Publishing.

Gamoran, A., Nystrand, M., Berends, M. and LePore, P. (I995) 'An organizational analysis of the effects of ability grouping', American Educational Research Journal 32(4): 687-7I 5 .

Grusec, J.E. and Goodnow, J.J. (I994) 'Impact of parental discipline methods on the child's internalization of values: a reconceptualization of currents points of view', Developmental Psychology 30(I): 4-I9.

Health Resources and Service Administration (n.d.) Working with Young People Who are Bullied: Tips for Mental Health Professionals. Washington, DC: Department of Health and Human Services. Available at http://stopbullyingnow.hrsa.gov/ HHS_PSA/pdfs/SBN_Tip_26.pdf (accessed 8 August 2009)

Isenberg, E.J. (2007) 'What have we learned about homeschooling?', Peabody Journal of Education 82: 387-409.

Jeub, C. (I994) 'Why parents choose homeschooling', Educational Leadership 52: $50-2$. 


\section{Theory and Research in Education 7(3)}

Kariya, T. and Rosenbaum, J. (I999) 'Bright flight: unintended consequences of de-tracking policy in Japan', American Journal of Education 107: 2 I0-30.

Kunzman, R. (2009) Write These Laws on Your Children: Inside the World of Conservative Christian Homeschooling. Boston, MA: Beacon Press.

Lubienski, C. (2000) 'Whither the common good? A critique of home schooling', Peabody Journal of Education 75(I-2): 229.

Mayberry, M. and Knowles, J.G. (I989) 'Family unity objectives of parents who teach their children: ideological and pedagogical orientations to home school', The Urban Review 21: 209-25.

Mayberry, M., Knowles, J.G., Ray, B.D. and Marlow, S. (1995) Homeschooling: Parents as Educators. Newbury Park, CA: Corwin Press.

Merry, M. S. (2008) 'Educational justice and the gifted', Theory and Research in Education 6(I): 47-70.

Ogbu, J. (I994) 'Racial stratification and education in the United States: why inequality persists', Teachers College Record 96(2): 264-98.

Rothermel, P. (2003) 'Can we classify motives for home education?', Evaluation and Research in Education I7 (2\&3): 74-89.

Shepherd, J. (2009) 'Clever Boys dumb down to avoid bullying'. Available at http://www.guardian.co.uk/education/2009/mar/29/education-schoolsbullying (accessed 8 August 2009).

Sidgwick, H. (I962 [1907]) Methods of Ethics. Chicago, IL: University of Chicago Press.

Snyder, T.D., Dillow, S.A. and Hoffman, C.M. (2009) Digest of Education Statistics 2008 (NCES 2009-020). Washington, DC: National Center for Education Statistics, Institute of Education Sciences, US Department of Education.

Spiegler, T. (2004) 'Home education in Germany: An overview of the contemporary situation', Evaluation and Research in Education I7: 179-90.

Stevens, M. (200I) Kingdom of Children: Culture and Controversy in the Homeschooling Movement. Princeton, NJ: Princeton University Press.

Swift, A. (2003) How Not to be a Hypocrite: School Choice for the Morally Perplexed Parent. London: Routledge.

Thomas, L. (2006) The Family and the Political Self. Cambridge: Cambridge University Press.

Van Galen, J.A. (1987) 'Explaining home education: parents' accounts of their decision to teach their own children', The Urban Review I9: I6I-77.

Van Galen, J.A. (I99I) 'Ideologues and pedagogues: Parents who teach their children at home', in J.A. Van Galen and M.A. Pitman (eds) Home Schooling: Political, Historical, and Pedagogical Perspectives, pp. 63-76. Norwood, NJ: Ablex.

Vedder, P. (2006) 'Black and White schools in the Netherlands', European Education 38(2): 36-49.

Wyatt, G. (2008) Family Ties: Relationships, Socialization, and Home Schooling. Lanham, MD: University Press of America. 
Merry and Howell: Can intimacy justify home education?

\section{B I O GRA PHICAL NOTE}

MICHAEL S. MERRY is Professor of Philosophy of Education and Chair of the Department of History and Philosophy in the Faculty of Social and Behavioural Sciences, University of Amsterdam. His philosophical and research interests include educational ethics, political philosophy, minority education and alternative pedagogies. [email: M.S.Merry@uva.nl]

CHARLES HOWELL is Associate Professor and Chair of the Department of Leadership, Educational Psychology, and Foundations at Northern Illinois University. He has written extensively on home schooling, equity and the legitimacy of school discipline. He recently completed a study of academic integrity of masters-level students and instructors. [email: chowell@niu.edu] 